\title{
Grupo de Pesquisa Informática na Educação INFOEDUC
}

\author{
Regina Barwaldt ${ }^{1}$ \\ ${ }^{1}$ Centro de Ciências Computacionais - Universidade Federal do Rio Grande (FURG) \\ Caixa Postal 474 - 96201-900 - Rio Grande - RS - RS - Brasil \\ \{reginabarwaldtefurg.br\}
}

Objetivo: O INFOEDUC tem como objetivo articular pesquisas nas áreas de Informática na Educação, que contemplam temas que envolvem a cognição e aprendizagem em ambientes virtuais; desenvolvimento de sistemas e recursos computacionais e suas implicações IHC; e educação, tecnologia e sociedade no contexto da inclusão digital.

Grupo Participante: Programa de Pós-Graduação em Modelagem Computacional e Computação oferecido pelo Centro de Ciências Computacionais (C3/FURG) e Curso de Pós-Graduação em Tecnologias da Informação e Comunicação na Educação, TICEDU, modalidade à distância, oferecido pela Secretária da Educação a Distância, SEAD/FURG.

Pesquisadores Envolvidos: André Luis de Castro Freitas, André Prisco Vargas, Diana Adamatti, Danúbia Bueno Espíndola, Ivete Martins Pinto, Rafael Augusto Penna dos Santos, Sílvia Silva da Costa Botelho e Vinícius Menezes de Oliveira.

Principais Projetos: Inclusão Digital, Tecnologias Assistivas, Tecnologia RFID e Formação de Professores.

Fomentos Recebidos: CNPQ, PROEXT 2014 e Bolsas de Iniciação Científica. 